05.2

\title{
Исследования диэлектрических свойств нефтяных дисперсных систем в зависимости от соотношения асфальтосмолистых веществ
}

\author{
(C) Р.Р. Зиннатуллин, Л.А. Ковалева
}

Башкирский государственный университет, Уфа, Россия

E-mail: rasulz@yandex.ru

Поступило в Редакцию 18 июня 2021 г.

В окончательной редакции 22 ноября 2021 г.

Принято к публикации 22 ноября 2021 г.

\begin{abstract}
Степень воздействия электромагнитного поля на нефтяные дисперсные системы зависит от диэлектрических свойств этих систем, в частности нефти. Диэлектрические свойства нефти зависят от содержания в ней высокомолекулярных полярных компонентов: асфальтенов и смол. В связи с этим проведено исследование диэлектрических свойств нефти в высокочастотном диапазоне в зависимости от содержания в ней асфальтосмолистых веществ. Полученные результаты экспериментальных исследований показывают корреляцию диэлектрических параметров с соотношением содержания в нефти смол и асфальтенов.
\end{abstract}

Ключевые слова: нефтяные дисперсные системы, асфальтосмолистые вещества, диэлектрические свойства, тангенс угла диэлектрических потерь, резонансная частота.

DOI: 10.21883/PJTF.2022.04.52084.18928

В последние годы в нефтедобывающей отрасли идут поиски новых технологий, направленных на интенсификацию добычи и улучшение качества добываемой продукции, основанных на использовании физических полей. В этом отношении наиболее применимыми и эффективными могут оказаться электромагнитные поля высокочастотного диапазона.

В процессах нефтедобычи электромагнитные поля могут использоваться для разогрева призабойной зоны пласта. Преимуществом электромагнитного нагрева является возможность распространения электромагнитных волн глубоко в пласт, что приводит к его нагреву. Нагрев пласта происходит за счет потерь энергии электромагнитного поля при распространении в пласте электромагнитных волн. Величина указанных потерь энергии зависит от параметров электромагнитной волны и диэлектрических свойств нефти и породы в целом [1-4].

В процессах нефтеподготовки электромагнитные поля высокочастотного диапазона могут быть эффективно использованы для обезвоживания нефти. Как известно, продукцией нефтедобывающих скважин являются высокоустойчивые водонефтяные эмульсии. Устойчивость эмульсий обеспечивается бронирующими оболочками, образованными вокруг глобул воды из полярных молекул нефти (асфальтены). Содержание в эмульсии полярных молекул нефти позволяет использовать электромагнитные поля высокочастотного диапазона для эффективного расслоения эмульсий $[5,6]$.

Также электромагнитные поля могут быть использованы для борьбы с отложениями в нефтепромысловом оборудовании и трубопроводах при транспортировке нефти $[7,8]$.

При всех упомянутых выше процессах степень взаимодействия электромагнитного поля с нефтяными дис- персными средами (нефти, нефтенасыщенные среды, водонефтяные эмульсии) зависит от диэлектрических свойств этих сред, которые в свою очередь зависят от содержания в нефти асфальтосмолистых веществ $[9,10]$. В зависимости от сорта нефти содержание асфальтенов и/или смол в нефти может достигать 20\%. Таким образом, исследование диэлектрических свойств нефти в зависимости от содержания асфальтосмолистых веществ является актуальной задачей. Цель настоящей работы состоит в исследовании диэлектрических свойств нефти в высокочастотном диапазоне в зависимости от содержания в ней асфальтосмолистых веществ.

В $[9,10]$ было показано, что диэлектрические свойства нефтяных дисперсных сред (водонефтенасыщенных горных пород и водонефтяных эмульсий) в большей степени зависят от сорта нефти. Поэтому в настоящей работе в качестве объекта исследования была использована реальная нефть с различным содержанием высокомолекулярных веществ (см. таблицу).

Содержание смол и асфальтенов, а также их соотношение в исследуемых сортах нефти

\begin{tabular}{c|c|c|c}
\hline $\begin{array}{c}\text { Сорт } \\
\text { нефти }\end{array}$ & $\begin{array}{c}\text { Асфальтены, } \\
\text { wt.\% }\end{array}$ & $\begin{array}{c}\text { Смолы, } \\
\text { wt.\% }\end{array}$ & Смолы/асфальтены $(R / A)$ \\
\hline 1 & 2.3 & 18.4 & 8.0 \\
2 & 2.6 & 15.2 & 5.8 \\
3 & 1.19 & 16.6 & 13.9 \\
4 & 3.2 & 11.4 & 3.6 \\
5 & 2.32 & 12.00 & 5.2 \\
6 & 10.71 & 3.26 & 0.3 \\
7 & 0.92 & 10.6 & 11.5 \\
8 & 0.67 & 6.2 & 9.3
\end{tabular}




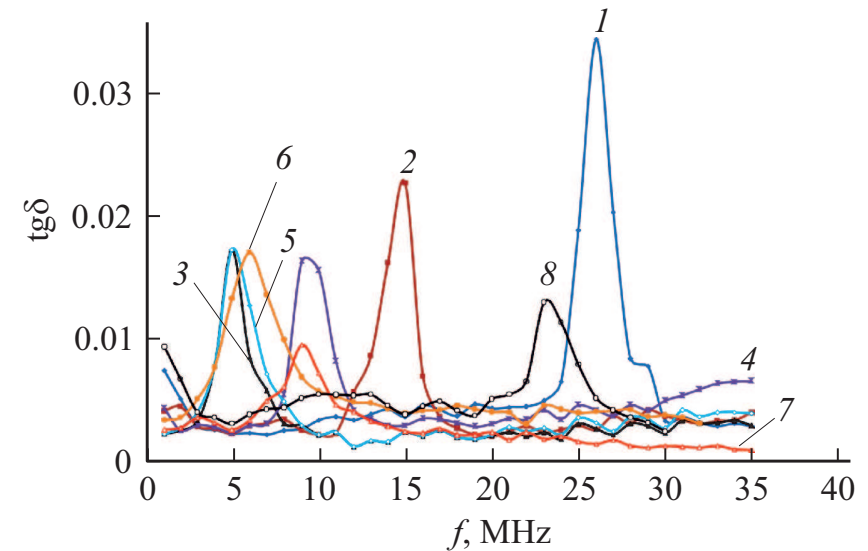

Рис. 1. Зависимости $\operatorname{tg} \delta(f)$ для исследуемых сортов нефти. Номера кривых соответствуют сортам нефти в таблице.

Диэлектрические свойства исследовались с использованием измерителя добротности ВМ 560 (диапазон частот 0.05-35 MHz) [11]. Частотные зависимости тангенса угла диэлектрических потерь $(\operatorname{tg} \delta)$ нефти изучались в диапазоне частот $0.1-35 \mathrm{MHz}$.

На рис. 1 представлены кривые $\operatorname{tg} \delta(f)$ для исследуемых сортов нефти. Из рисунка видно, что кривые $\operatorname{tg} \delta(f)$ имеют резонансный вид с резонансной частотой $f_{\text {res }}$ и соответствующим ей значением тангенса угла диэлектрических потерь $\operatorname{tg} \delta_{m}$. Ширина резонансной кривой соответствует области поляризации присутствующих в нефти полярных компонентов, которая может находиться в разных частотных диапазонах. Это указывает на разные времена релаксации диэлектрической поляризации полярных компонентов для разных сортов нефти. Согласно соотношению, предложенному Дебаем [12]:

$$
f_{\text {res }}=\frac{k T}{4 \pi \eta a^{3}}
$$

(где $f_{\text {res }}$ - резонансная частота, соответствующая максимуму тангенса угла диэлектрических потерь $\operatorname{tg} \delta_{m}$, $k$ - постоянная Больцмана, $T$ - температура, $\eta-$ вязкость жидкости, $a$ - радиус сферической молекулы), которое связывает время релаксации с молекулярными постоянными, на частотах $1-30 \mathrm{MHz}$ диэлектрической поляризацией обладают молекулы размером 1-2 nm.

Такой размер имеют отдельные молекулы асфальтенов. Смолы имеют размер, на порядок меньший, и стабилизируют отдельные молекулы асфальтенов, адсорбируясь на их поверхности. В отсутствие смол асфальтены объединяются в наноагрегаты, кластеры и агломераты [13-15].

Сравнительный анализ значений $\operatorname{tg} \delta_{m}$ для разных сортов нефти в зависимости от содержания в них высокомолекулярных соединений (асфальтенов, смол, парафинов) показал, что имеется корреляция между $\operatorname{tg} \delta_{m}$ и соотношением смол и асфальтенов в нефти. На рис. 2 представлены зависимости значений $\operatorname{tg} \delta_{m}$ от соотношения содержания смол и асфальтенов в нефти $(R / A)$.

Видно, что при соотношении смол и асфальтенов, равном $8 / 1$, на зависимости $\operatorname{tg} \delta_{m}$ от $R / A$ наблюдается максимум. Это свидетельствует о том, что именно при таком соотношении $R / A$ асфальтены полностью пептизируются и стабилизируются смолами, т. е. асфальтены перестают существовать в виде агломератов и становятся более мобильными для участия в процесcax поляризации. При соотношении выше 8/1 значения $\operatorname{tg} \delta_{m}$ снижаются, т.е. полярность нефти уменьшается. Возможно, в избытке молекулы смол, адсорбируясь на молекулы асфальтенов, образуют вокруг них оболочку, состоящую из нескольких слоев, тем самым изолируя и укрупняя их.

Аналогичная кривая получена для величины резонансной частоты в зависимости от соотношения $R / A$ (рис. 3 ).

Из рис. 3 видно, что с ростом соотношения $R / A$ до значения 8/1 резонансная частота $f_{\text {res }}$, а следовательно, и область поляризации молекул асфальтенов смещаются в область высоких частот, т. е. время диэлектрической релаксации уменьшается. Этот факт также объясняет-

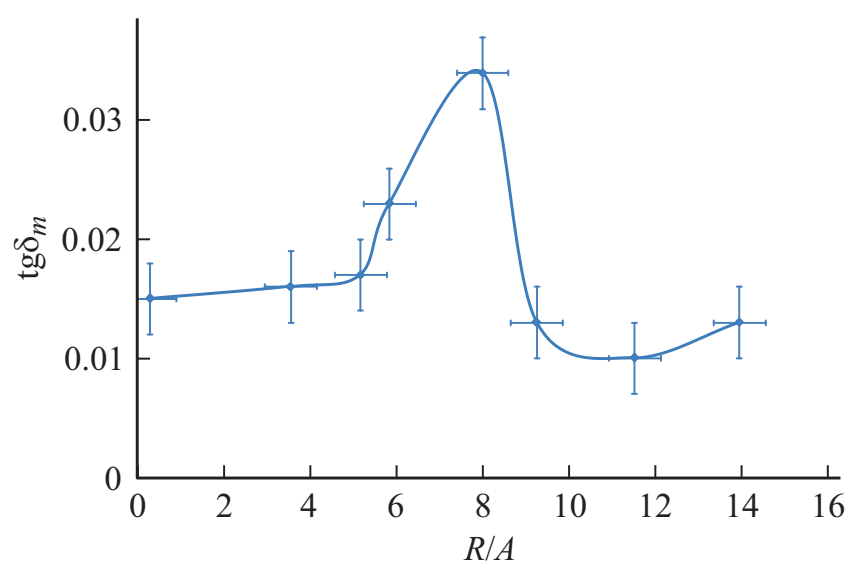

Рис. 2. Зависимость $\operatorname{tg} \delta_{m}$ от соотношения содержания смол и асфальтенов $(R / A)$ в нефти.

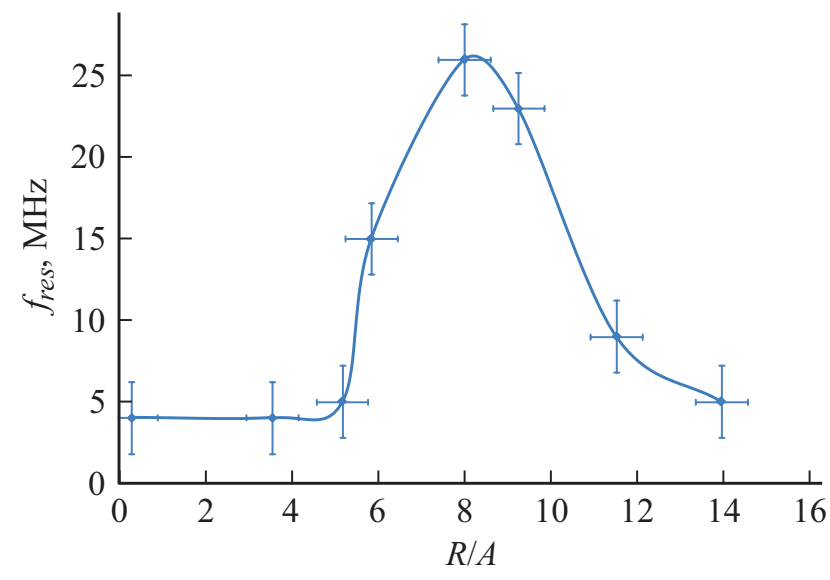

Рис. 3. Зависимость резонансной частоты от соотношения содержания смол и асфальтенов $(R / A)$ в нефти. 
ся расщеплением асфальтеновых агломератов смолами. При бо́льших $R / A$ резонансная частота смещается в область низких частот. Этот факт свидетельствует об укрупнении полярных молекул, участвующих в процессе поляризации.

В результате проведенных исследований обнаружено, что значение тангенса угла диэлектрических потерь, соответствующее резонансной частоте дипольной поляризации молекул асфальтенов, растет с ростом соотношения содержания смол и асфальтенов в нефти. Также обнаружено, что с ростом этого соотношения резонансная частота поляризации молекул асфальтенов, а следовательно, и область их поляризации смещаются в область высоких частот, т.е. время диэлектрической релаксации уменьшается, что объясняется расщеплением асфальтеновых агломератов смолами с ростом соотношения $R / A$.

Полученные результаты будут полезны при разработке рекомендаций для промышленного использования высокочастотного электромагнитного воздействия на нефтяные дисперсные системы, такие как нефтенасыщенные пласты и водонефтяные эмульсии.

\section{Финансирование работы}

Исследования выполнены за счет гранта Российского научного фонда (проект № 19-11-00298).

\section{Конфликт интересов}

Авторы заявляют, что у них нет конфликта интересов.

\section{Список литературы}

[1] В.А. Балакирев, Г.В. Сотников, Ю.В. Ткач, Т.Ю. Яценко, Электромагнитные явления, 2 (2), 6 (2001). DOI: $10.1016 / \mathrm{S} 0927-7757(03) 00079-7$

[2] Л.А. Ковалева, Р.Р. Зиннатуллин, Р.Ф. Султангужин, Э.С. Сектаров, А.В. Шашков, Вестн. Башкир. ун-та, 24 (1), 43 (2019).

[3] Л.А. Ковалева, Р.Р. Зиннатуллин, Р.Ф. Султангужин, И.И. Шрубковский, А.В. Мясников, ТВТ, 55 (5), 858 (2017). DOI: 10.7868/S0040364417050118 [L.A. Kovaleva, R.R. Zinnatullin, R.F. Sultanguzhin, I.I. Shrubkovski, A.V. Myasnikov, High Temp., 55 (5), 837 (2017). DOI: $10.1134 / \mathrm{S} 0018151 \mathrm{X} 17050108]$.

[4] И.Л. Хабибуллин, Ф.Ф. Назмутдинов, Вестн. Башкир. ун-та, 19 (2), 381 (2014).

[5] L.A. Kovaleva, R.Z. Minnigalimov, R.R. Zinnatullin, Energy Fuels, 25 (8), 3731 (2011). DOI: 10.1021/ef200249a

[6] Л.А. Ковалева, Р.Р. Зиннатуллин, А.И. Муллаянов, М.В. Мавлетов, В.Н. Благочиннов, ТВТ, 51 (6), 952 (2013). DOI: 10.7868/S0040364413060173 [L.A. Kovaleva, R.R. Zinnatullin, A.I. Mullayanov, M.V. Mavletov, V.N. Blagochinnov, High Temp., 51 (6), 870 (2013). DOI: 10.1134/S0018151X13060175].

[7] В.А. Балакирев, Г.В. Сотников, Ю.В. Ткач, Т.Ю. Яценко, Электромагнитные явления, 2 (3), 7 (2001).
[8] Л.А. Ковалева, Р.Р. Зиннатуллин, М.Д. Валеев, Р.3. Миннигалимов, Р.Х. Фассахов, Нефтяное хозяйство, № 2, 82 (2019). DOI: 10.24887/0028-2448-2019-2-82-85

[9] Р.Р. Зиннатуллин, Л.А. Ковалева, Р.Ф. Султангужин, ТВТ, 57 (1), 143 (2019). DOI: 10.1134/S0040364419010253

[R.R. Zinnatullin, L.A. Kovaleva, R.F. Sultanguzhin, High Temp., 57 (1), 127 (2019). DOI: $10.1134 / \mathrm{S} 0018151 \mathrm{X} 19010243]$.

[10] Л.А. Ковалева, Р.3. Миннигалимов, Р.Р. Зиннатуллин, ТВТ, 46 (5), 792 (2008). [L.A. Kovaleva, R.Z. Minnigalimov, R.R. Zinnatullin, High Temp., 46 (5), 728 (2008). DOI: $10.1134 / \mathrm{S} 0018151 \mathrm{X} 08050210]$.

[11] А.А. Брандт, Исследование диэлектриков на сверхвысоких частотах (Физматгиз, М., 1963).

[12] П. Дебай, Полярные молекулы (ГТТИ, М.-Л., 1931).

[13] J.J. Adams, Energy Fuels, 28 (5), 2831 (2014). DOI: $10.1021 /$ ef500282p

[14] J.G. Speight, Oil Gas Sci. Technol., 59 (5), 467 (2004). DOI: $10.2516 /$ ogst:2004032

[15] P.M. Spiecker, K.L. Gawrys, C.B. Trail, P.K. Kilpatrick, Coll. Surf. A, 220 (1-3), 9 (2003). DOI: $10.1016 / \mathrm{S} 0927-7757(03) 00079-7$ 